\title{
Photochemistry of 2-Oxoacetates: from Mechanistic Insights to Profragrances and Bursting Capsules
}

\author{
Andreas Herrmann* \\ Dedicated to Prof. Bernd Giese on the occasion of his $80^{\text {th }}$ birthday
}

\begin{abstract}
Photoirradiation of 2-oxoacetates ( $\alpha$-ketoesters) with UV-A light proceeds via an intramolecular hydrogen abstraction of the triplet state in a Norrish type II pathway to form carbonyl compounds, carbon monoxide and/or dioxide, and a series of other side products. This review gives a detailed overview of the mechanistic aspects of photooxidation by explaining the pathways that yield the major products formed in the presence or absence of oxygen. Furthermore, it demonstrates how the photoreaction can be used for the light-induced controlled release of fragrances from non-polymeric profragrances, polymer conjugates and core-shell microcapsules in applications of functional perfumery. In the case of microcapsules, the gas formation accompanying the Norrish type II fragmentation can generate an overpressure that expands or cleaves the capsule wall to release fragrances and thus provides access to multi-stimuli responsive delivery systems.
\end{abstract}

Keywords: Delivery systems · Fragrance encapsulation · Norrish type II reactions · Photochemistry · Properfumes

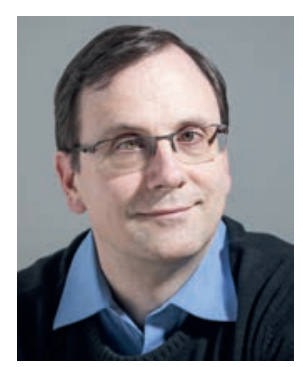

Andreas Herrmann is a Principal Scientist at the corporate R\&D division of Firmenich SA in Genève (Switzerland). He studied chemistry at the University of Karlsruhe (Germany) and the Ecole de Chimie (EHICS) in Strasbourg (France). In 1997, he obtained a PhD from the ETH Zürich (Switzerland) under the guidance of Prof. François Diederich. In the same year, he joined Firmenich as a research scientist, where he has been working on the development of fragrance delivery systems (profragrances) for now more than 20 years. He has also lectured at the University of Fribourg (Switzerland) for 10 years. In 2016, he received the KGF-SCS Industrial Science Award from the Swiss Chemical Society (SCS) and the Contact Group for Research Matters (KGF) for his work on profragrances. $\mathrm{He}$ is author or co-author of 70 scientific publications and more than 25 patents.

\section{Introduction}

Perfumes, an important part of modern body and home care products such as shower gels, shampoos, surface cleaners and fabric treatment products, provide a pleasant odour on the target surface to which they are applied. As a consequence of their high volatilities, fragrances rapidly evaporate from these surfaces, which considerably limits the time of the desired perfuming effect. The controlled release of fragrances for long-lasting odour perception has become an important research area in the flavour and fragrance industry. Two major strategies, namely the encapsulation of fragrances (physical delivery systems) ${ }^{[1]}$ and their in situ generation by covalent bond cleavage from suitably designed precursors, so-called profragrances or properfumes (chemical de- livery systems), ${ }^{[2]}$ have been explored as complementary delivery technologies in this context.

Light is a suitable trigger for releasing fragrances from both capsules $^{[3-6]}$ and profragrances. ${ }^{[6-15]}$ The UV-A part of natural daylight provides enough energy for the isomerisation and cleavage of covalent bonds, and the premature degradation of the delivery systems during storage can be avoided by the choice of opaque packing materials. To perform under everyday application conditions, the photochemical transformations used for the fragrance release have to proceed in a polar environment, preferably in water, at usually low and varying intensities of ambient daylight, and allow the presence of oxygen.[14] A reaction that fulfils these criteria, and that has been explored for the controlled release of fragrances from profragrances, is the Norrish type II reaction. ${ }^{[11,12,16,17]}$ It tolerates broad structural variability, and, depending on the selected precursor structure, the light-induced generation of different alkenes, aldehydes, ketones, esters or lactones is possible.[11] 2-Alkyl- or 2-aryl-2-oxoacetates ( $\alpha$-ketoesters) represent a particular group of precursors that form aldehydes and ketones upon photooxidation at $350-370 \mathrm{~nm}$. They can readily be prepared from commercially available starting materials and thus might be suitable as profragrances for the controlled release of volatile compounds. ${ }^{[6-11]}$

The present review focuses on the general mechanism of the photofragmentation of 2-oxoacetates, the understanding of which is a basic requirement to optimise the corresponding fragrance delivery systems to perform under natural environmental conditions. We then discuss the development of a variety of non-polymeric and polymeric 2-oxoacetate profragrances as delivery systems in functional perfumery and conclude with some aspects concerning the light-induced release of fragrances by using 2-oxoacetates encapsulated in core-shell microcapsules. 


\section{Mechanistic Aspects for the Light-induced Cleavage of 2-Oxoacetates}

In 1961, Hammond, Leermakers and Turro reported that the photoirradiation of ethyl pyruvate in toluene afforded acetaldehyde and carbon monoxide, together with small amounts of carbon dioxide (Scheme 1). ${ }^{[18]}$ With sensitisation experiments, they also showed that the process proceeded through an excited triplet state.

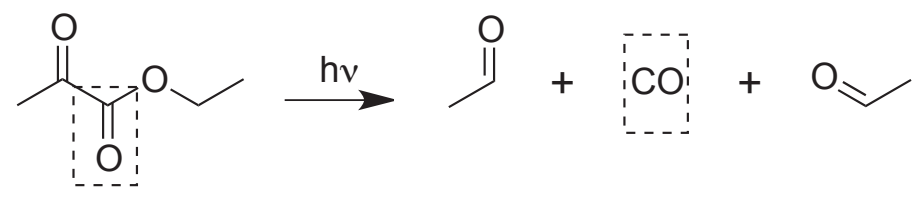

Scheme 1. Photolysis of ethyl pyruvate in toluene reported by Hammond, Leermakers and Turro in 1961. ${ }^{[18]}$

Following this initial publication, the work of several research groups established the mechanism for the photofragmentation of 2-alkyl-and 2-aryl-2-oxoacetates (A), which is outlined in Scheme 2. Upon photoirradiation of 2-oxo-2-phenylacetates $(\mathbf{A}, \mathrm{R}=\mathrm{Ph})$ in alcoholic solution, Huyser and Neckers observed the formation of photoreduced dimer $\mathbf{B}$ at low temperatures $\left(\mathrm{ca} .30^{\circ} \mathrm{C}\right)$ and the formation of hydroxyester $\mathbf{C}$ together with carbonyl derivative D at higher temperatures $\left(78^{\circ} \mathrm{C}\right) \cdot{ }^{[19]}$ To explain the findings at elevated temperatures, they proposed an intermediate 1,4-diradical $\mathbf{E}$ obtained by intramolecular $\gamma$-hydrogen abstraction from the excited triplet state $\mathbf{F}$. Fragmentation of $\mathbf{E}$ then forms carbonyl derivative $\mathbf{D}$ and hydroxyketene $\mathbf{G}$, the latter of which reacts with the solvent alcohol to give hydroxyester $\mathbf{C} .{ }^{[19]}$ In the presence of water, the corresponding hydroxycarboxylic acid is obtained via its enol. ${ }^{[20]}$ The formation of dimeric reaction product $\mathbf{B}$ has been explained by intermolecular hydrogen abstraction of $\mathbf{F}$ from the solvent to give radical $\mathbf{H}$, which then dimerises. Simultaneously, Yang and Morduchowitz investigated the irradiation of ethyl pyruvate in isopropanol and in cyclohexane and, in analogy to the Norrish type II reaction of ketones, ${ }^{[11,16,17]}$ expected the reaction to proceed via intramolecular $\gamma$-hydrogen abstraction to form hydroxyketene $\mathbf{G} .{ }^{[21]}$ However, with the photolysis being carried out at low temperature, they observed only the formation of the reductive dimerisation product $\mathbf{B}$ and small amounts of $\mathbf{I}$ in both cases. At that stage, the origin of the carbon monoxide reported by Hammond et al. ${ }^{[18]}$ could not be rationalised. However, the formation of the corresponding intermediate ketyl radicals, which are required to explain the observed reaction products, has been confirmed by electron paramagnetic resonance spectroscopy.[22]

As an alternative mechanism, the loss of carbon monoxide has been proposed as the primary step of the reaction to form an acyl and alkoxy radical, which then disproportionate. ${ }^{[23]}$ This suggestion was essentially based on the observation that 2-oxoacetates with different ester groups (methyl, ethyl or isopropyl) decomposed with similar quantum efficiencies, while a hydrogen transfer as the primary process was expected to result in different structure-dependent quantum yields. Alternatively, the photodecarbonylation of 2-oxoacetates to form esters and carbon monoxide has been proposed. ${ }^{[24]}$ Both mechanisms would explain the formation of carbon monoxide that was originally reported by Hammond et al. ${ }^{[18]}$

Almost 20 years later, Davidson and Goodwin reassessed the reaction and found that tert-butyl pyruvate with no abstractable $\gamma$-hydrogen atom was photostable, thus confirming the intramolecular $\gamma$-hydrogen abstraction process. ${ }^{[25]}$ From product studies and laser flash photolysis experiments, Scaiano and co-workers further supported the Norrish type II reaction from a triplet state via 1,4-diradical $\mathbf{E}$ and hydroxyketene $\mathbf{G}$ as the major pathway in the photolysis of both 2-alkyl- and 2-aryl-2-oxoacetates in solution. ${ }^{[26}$
Detailed mechanistic studies, which completed the structures shown in Scheme 2, were carried out by Hu and Neckers in the 1990 s with the example of 2-aryl-2-oxoacetates $(\mathrm{R}=\mathrm{Ph}) .[10,27]$ Quantitative product analyses, e.g. for the irradiation of ethyl 2-oxo-2-phenylacetate (1, Scheme 3) in benzene, afforded carbonyl compound $\mathbf{D}$ (here: acetaldehyde) and aldehyde $\mathbf{J}$ (here: benzaldehyde) as the major reaction products, together with the dimeric structure corresponding to $\mathbf{B}$ and small amounts of $\mathbf{K}, \mathbf{L}$ and $\mathbf{M}$ (Schemes 2 and 3). ${ }^{[27]}$

The formation of the different reaction products has been explained as a result of intramolecular $\gamma$-hydrogen abstraction from the excited triplet state $\mathbf{F}$ to form 1,4-diradical $\mathbf{E}$ on the one hand, and of intermolecular hydrogen abstraction to form radicals $\mathbf{H}$ and $\mathbf{N}$ on the other hand (Scheme 2).[27]

Overall, the photoirradiation of 2-oxoacetate A first generates an electronic $n-\pi^{*}$ transition from the ground state of the carbonyl group to the excited singlet state $\mathbf{O}$, which is then transformed to the reactive triplet state $\mathbf{F}$ by rapid intersystem crossing (ISC). [26,27] Intramolecular $\gamma$-hydrogen abstraction (Norrish type II process) produces carbonyl compound $\mathbf{D}$ and hydroxyketene G. By loss of carbon monoxide, $\mathbf{G}$ forms an intermediate carbene species that rearranges to aldehyde $\mathbf{J},{ }^{[28]}$ rather than a methyl- or phenylglyoxal, which has previously been proposed to be at the origin of carbon monoxide formation but has never been observed. ${ }^{[19,20,25,27]}$ Intermolecular hydrogen abstraction from the reactive triplet $\mathbf{F}$ can occur either from the solvent to give $\mathbf{H}$ or from the ester side chain of $\mathbf{A}$ by the triplet of a second molecule of $\mathbf{A}$ to yield $\mathbf{N}$. While $\mathbf{H}$ abstracts a hydrogen atom to give $\mathbf{I}$ or dimerises to give $\mathbf{B}$ (as outlined earlier), $\mathbf{N}$ splits into radical $\mathbf{P}$ and carbonyl compound D. ${ }^{[27]}$ Upon loss of carbon monoxide, $\mathbf{P}$ can then form radical $\mathbf{Q}$ and (upon hydrogen abstraction) react further to form aldehyde $\mathbf{J}$. Alternatively, radical $\mathbf{Q}$ can also couple with $\mathbf{P}$ to form $\mathbf{L}$ or, alternatively, upon addition to $\mathbf{A}$ give rise to compound $\mathbf{K}$. Similarly, the formation of $\mathbf{M}$ might be explained by addition of an acetyl radical to $\mathbf{A}$ and hydrogen abstraction. ${ }^{[27]}$

Time-resolved infrared spectroscopy showed the presence of two triplet state conformers, only one of which $(\mathbf{F})$ can adopt the suitable conformation of the transition state for the Norrish type II reaction. ${ }^{[29]}$ Furthermore, a possible bimolecular process for the formation of ketene $\mathbf{G}$, especially at high 2-oxoacetate concentrations, and the rapid formation of benzoyl radicals $(\mathbf{Q})$ from a Norrish type I process have been proposed.[30] Determination of quantum yields and initial rate constant measurements have shown that the ratio between intramolecular and intermolecular hydrogen abstraction depended on the concentrations of the starting materials, with the intramolecular fragmentation pathway dominating at lower product concentrations. ${ }^{[27]}$ For the targeted application of 2-oxoacetates for the light-induced release of fragrance aldehydes and ketones, it is important to note that the targeted carbonyl compound $\mathbf{D}$, as well as aldehyde $\mathbf{J}$ and carbon monoxide, can be formed from both intramolecular and intermolecular hydrogen abstraction, while the undesired side products $\mathbf{B}$ and $\mathbf{K}-\mathbf{M}$ are obtained only by intermolecular hydrogen abstraction. Because the corresponding profragrances will be used only at small dosages in practical applications, the dominance of the intramolecular $\gamma$-hydrogen abstraction at low concentrations will be favourable for limiting the formation of these unwanted side products.

So far, the mechanism summarised in Scheme 2 has been determined in degassed solution. However, because molecular oxygen efficiently traps carbonyl triplet states and interacts with diradicals, as shown for closely related systems, ${ }^{[31]}$ its role in the Norrish type II photofragmentation of 2-oxoacetates will be crucial in view of the desired practical applications. Davidson et al. observed that the presence of oxygen increased the formation of carbon dioxide, and presented evidence that singlet oxygen was 
not involved in the decarboxylation reactions. ${ }^{[32]}$ They proposed that an electron transfer from the excited 2-oxoacetate to oxygen led to the formation of peracid intermediates, which would be in competition with the Norrish type II process.

Pirrung and Tepper, ${ }^{[33]}$ as well as Hu and Neckers, ${ }^{[34]}$ reported that the presence of oxygen did not significantly influence the Norrish type II reaction of 2-oxoacetates, but resulted in different by-products with different yields. Because of the formation of benzoic acid $\mathbf{R}$ and carbon dioxide, which were obtained togeth- er with carbonyl compound $\mathbf{D}$ in the photolysis of 2-aryl-2-oxoacetates $(\mathrm{R}=\mathrm{Ph})$, it has been proposed that oxygen reacts with 1,4-diradical $\mathbf{E}$ to form peroxydiradical $\mathbf{S}$ that cyclises to 1,3,4-trioxane intermediate $\mathbf{T}$. Rearrangement of $\mathbf{T}$ then yields the final products. Interestingly, depending on how $\mathbf{T}$ rearranges, either carboxylic acid $\mathbf{R}$, carbon dioxide and carbonyl compound $\mathbf{D}$ are formed, or oxygen, carbonyl compound $\mathbf{D}$ and hydroxyketene $\mathbf{G}$ (yielding aldehyde $\mathbf{J}$ and carbon monoxide as outlined earlier) are obtained. ${ }^{[33,34]}$ This might explain the simultaneous formation of

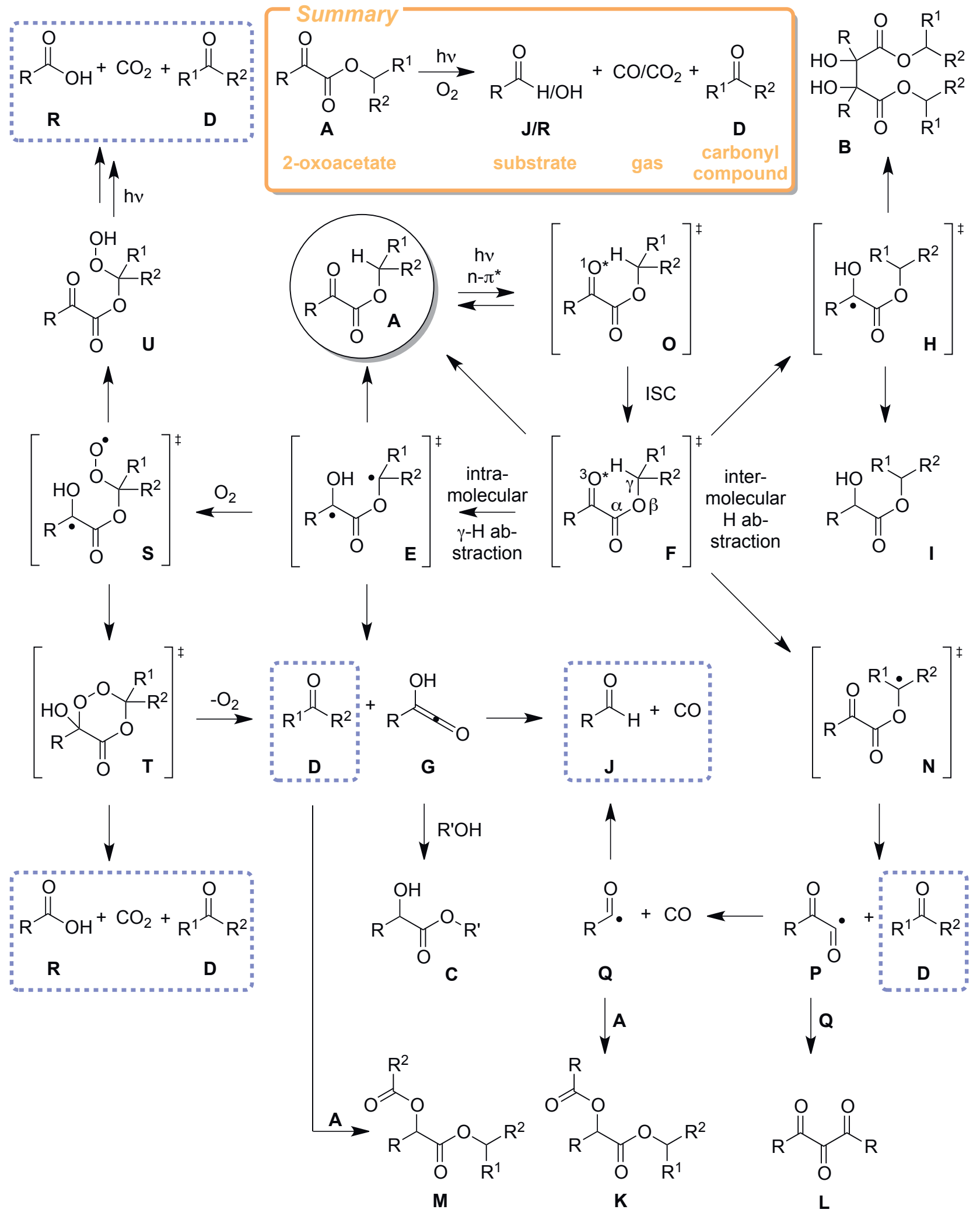

Scheme 2. General mechanism for the photofragmentation of 2-alkyl- and 2-aryl-2-oxoacetates in solution. The major reaction products obtained in degassed solution ( $\mathbf{D}, \mathbf{J}$ and $\mathrm{CO}$ ) or in the presence of oxygen ( $\mathbf{D}, \mathbf{J}, \mathbf{R}, \mathrm{CO}$ and $\mathrm{CO}_{2}$ ) are highlighted in dotted boxes. 
<smiles>CCOC(=O)C(=O)c1ccccc1</smiles>

$1(0 \%)$

\begin{tabular}{c|c}
$\mathrm{h} v$ & $\begin{array}{c}\text { degassed } \\
\text { benzene }\end{array}$
\end{tabular}<smiles>CC(=O)c1ccccc1</smiles>

$\mathbf{J}(33 \%) \quad$ D $(46 \%)$<smiles>CCOC(=O)C(O)(C(=O)OCC)C(O)(c1ccccc1)c1ccccc1</smiles>

B $(19 \%)$<smiles>O=C(C(=O)c1ccccc1)C(=O)c1ccccc1</smiles>

$\mathbf{L}(3 \%)$<smiles>CCOC(=O)C(OC(=O)c1ccccc1)c1ccccc1</smiles>

K $(4 \%)$<smiles>CCOC(=O)C(OC(C)=O)c1ccccc1</smiles>

$\mathbf{M}(1 \%)$
Scheme 3. Products isolated from the photoirradiation of 2-aryl-2-oxoacetate 1 in degassed benzene (at $350 \mathrm{~nm}$ for $120 \mathrm{~min}$ ). ${ }^{[27]}$ Letters correspond to the general structures indicated in Scheme 2 (with $R=P h, R^{1}$ $\left.=\mathrm{H}, \mathrm{R}^{2}=\mathrm{Me}\right)$. The mol-\% given in parentheses were calculated from the respective product concentrations indicated in the literature. ${ }^{[27]}$

$\mathbf{J}, \mathbf{R}$, carbon monoxide and carbon dioxide together with carbonyl compound $\mathbf{D}$ generally observed in photoirradiations carried out in the presence of oxygen. Finally, a hydrogen shift in $\mathbf{S}$ can form hydroperoxide $\mathbf{U}$, which, as an unstable photolabile 2-oxoacetate derivative, is supposed to rapidly fragment in several steps (not shown in Scheme 2) to afford carboxylic acid $\mathbf{R}$, carbonyl compound $\mathbf{D}$, carbon dioxide and possibly small amounts of $\mathbf{K}$ as the final products. ${ }^{[34]}$

The reaction is quite robust, and 2-oxoacetates have been proposed as photoremovable protecting groups for the preparative photooxidation of primary or secondary alcohols to aldehydes or ketones. ${ }^{[33,35,36]}$ The mechanistic studies summarised in Scheme 2 suggested that the light-induced generation of aldehydes and ketones might work under realistic application conditions. The desired Norrish type II photooxidation has been found to be the dominant reaction pathway at low concentrations in aprotic solvents and in the presence of oxygen. However, protic solvents with readily abstractable hydrogen atoms are susceptible to giving rise to a larger amount of undesired side reactions. Furthermore, because ambient daylight is subject to constant seasonal, daily and hourly fluctuations, ${ }^{[37]}$ one can expect a considerable impact of variable light intensities on the efficiency of the delivery system in practical application. And finally, the reaction has to work with various product formulations and practical application concepts encountered in functional perfumery. In the next section, we use the knowledge gained from the mechanistic studies and discuss the light-induced release of different fragrance aldehydes and ketones from profragrances under more realistic everyday life conditions.

\section{Profragrances Based on 2-Oxoacetates}

\subsection{Non-polymeric Systems}

Our main goal with a profragrance is to prolong the olfactive perception of the corresponding fragrance in time. This is typically achieved by covalently linking the fragrance to a suitable substrate, which makes the final profragrance less volatile. ${ }^{[2]}$ The choice of the profragrance chemistry, here light-induced photooxidation to generate aldehydes or ketones, defines the functional groups of fragrances that can be released. Many common fragrance materials are aldehydes or ketones, which represent a multitude of olfactive notes and cover large structural variability from about 5 or 6 , to 15 or more carbon atoms. ${ }^{[38,39]}$ Apart from the desired olfactive note and the volatility of the fragrance to be released (vapour pressures of typical fragrances span several orders of magnitude), suitable profragrances have to be compatible with the desired application in terms of release rates, storage stability, efficiency of deposition on the target surface, toxicity, biocompatibility and cost. ${ }^{[2]}$

As a first step to assess the performance of 2-oxoacetates as profragrances, compounds $( \pm)-2-( \pm)-8$ have been prepared, ${ }^{[7]}$ which all release citronellal that has a fresh, green-citrusy odour ${ }^{[40]}$ (Fig. 1). Xenon lamps are commonly used to simulate sunlight under laboratory conditions, ${ }^{[41]}$ with the advantage of providing a constant light intensity over time compared with the generally changing irradiance of natural sunlight. Comparable amounts of fragrances were released upon photoirradiation of undegassed solutions of the profragrances with a xenon lamp and with outdoor sunlight for $3 \mathrm{~h},{ }^{[7]}$ thus confirming the use of a xenon lamp as an equivalent to ambient daylight.

Depending on the structure of the profragrance and the solvent used for photolysis, ${ }^{[35]}$ the amount of fragrance released varied from a few percent up to about $55 \% .{ }^{[7]}$ Systematic GC/MS measurements of the irradiated solutions, as well as preparative GC combined with NMR spectroscopy, allowed the identification of a series of side products formed in the reaction.

In addition to the desired citronellal, another compound, which had been assigned as ( \pm )-6,7-epoxy-3,7-dimethyloctanal $(( \pm)-9$, Scheme 4), has systematically been obtained, independent of the structure of the 2-oxoacetate (alkyl-, cycloalkyl- or aryl-) and of the solvent used for the irradiation. ${ }^{[7]}$ Synthesis of the cor-<smiles>[R]C(=O)C(=O)OCCC(C)CCC=C(C)C</smiles>
$( \pm)-2: \mathrm{R}=\mathrm{CH}_{3}$
$( \pm)-3: \mathrm{R}=\mathrm{CH}_{2} \mathrm{CH}_{3}$
$( \pm)-4: \mathrm{R}=\mathrm{CH}_{2} \mathrm{CH}_{2} \mathrm{CH}_{3}$ alkyl
$( \pm)-5: \mathrm{R}=\mathrm{CH}\left(\mathrm{CH}_{3}\right) \mathrm{C}_{12} \mathrm{H}_{25}$
$( \pm)-6: \mathrm{R}=\mathrm{C}_{5} \mathrm{H}_{9}$
$( \pm)-7: \mathrm{R}=\mathrm{C}_{6} \mathrm{H}_{11}$
$( \pm)-8: \mathrm{R}=\mathrm{C}_{6} \mathrm{H}_{5}$ cycloalkyl

Fig. 1. Structures of citronellal-releasing 2-alkyl-, 2-cycloalkyl- and 2-aryl-2-oxoacetate profragrances $( \pm)-2-( \pm)-8 .{ }^{[7]}$ 
responding epoxidised profragrances confirmed their presence in most of the irradiated solutions, as shown by GC/MS analysis. Epoxidation of the citronellyl double bond can thus take place after its release from the profragrance in the Norrish type II reaction or at the stage of the profragrance, which once epoxidised, releases ( \pm ) 9 by the expected Norrish type II photofragmentation (Scheme 4). ${ }^{[7]}$ Epoxidation of olefins in the presence of 2-oxoacetates has previously been described to result from a photochemical $\alpha$-cleavage, which forms an acylperoxy radical and then transfers an oxygen atom to the alkene. ${ }^{[42]}$

Photoirradiation of 2-alkyl-2-oxoacetates $( \pm)-4$ and $( \pm)-5$ yielded the corresponding profragrances $( \pm)-\mathbf{2}$ and $( \pm)-\mathbf{3}$ with shorter alkyl chains, respectively. In the case of $( \pm)-\mathbf{5}$, dodecene has been identified as an additional side product. This observation has been rationalised by $\gamma$-hydrogen abstraction from the alkyl chain instead of the ester chain of the 2-oxoacetates. ${ }^{[43]} \mathrm{Ab}$ initio density-functional calculations of the two triplet 1,4-diradicals revealed that the structure resulting from $\gamma$-hydrogen abstraction of the alkyl chain is almost $1 \mathrm{kcal} \mathrm{mol}^{-1}$ more stable than the diradical formed by $\gamma$-hydrogen abstraction from the ester chain (Scheme 5). ${ }^{[7]}$ It has further been demonstrated by X-ray crystal structure analysis that the $\gamma$-hydrogen atom has to be at a $\mathrm{C}=\mathrm{O} \cdots \mathrm{H}$ distance close to the van-der-Waals radii of about $2.7 \AA$ to be efficiently abstracted. ${ }^{[44]}$ Calculation of the relative energies required to adopt the favourable conformations for $\gamma$-hydrogen abstraction showed that the rotation of the alkyl chain required $0.5 \mathrm{kcal}$ $\mathrm{mol}^{-1}$, while that of the ester chain needed $7.4 \mathrm{kcal} \mathrm{mol}^{-1}$ (Scheme 5). ${ }^{[7]}$ Comparable results have been predicted from other calculations. ${ }^{[45,46]}$ Because alkyl chain fragmentation forms a 2-oxoacetate with a shorter alkyl chain that can further react by ester chain fragmentation to release the fragrance aldehyde, this side reaction is not necessarily problematic for the desired practical application. If desired, alkyl chain fragmentation can be used to release fragrance alkenes or can be avoided by using 2-cycloalkyl- or 2-aryl-2-oxoacetates as precursors.

Finally, the photolysis of 2-aryl-2-oxoacetate ( \pm -8 8 in degassed or undegassed solvents afforded oxetane $( \pm)-\mathbf{1 0}$ as an additional side product ${ }^{[7,10,46]}$ resulting from an intramolecular Paternò-Büchi cycloaddition (Fig. 2). ${ }^{[47]}$ Competition between the Norrish type II photofragmentation and the (inter- or intramolecular) PaternòBüchi cycloaddition generally occurs in the presence of alkenes; electron-rich alkenes such as enol ethers and multi-alkyl-substituted olefins are in particular favourable for alkene addition. ${ }^{[46,48-50]}$ Although previously reported for intermolecular cycloadditions, ${ }^{[49]}$ intramolecular oxetane formation has not been observed for the photolysis of 2-alkyl- or 2-cycloalkyl-2-oxoacetates. ${ }^{[7]}$

The Paternò-Büchi cycloaddition is stereoselective. ${ }^{[46-48]}$ Depending on the orientation of the citronellyl double bond with respect to the carbonyl group, oxetanes $( \pm)-\mathbf{1 0}$ or $( \pm)$-11 can theoretically be formed, but only the structure of $( \pm)$-10 was in agreement with the NMR data of the isolated product. ${ }^{[7,10]}$ The selective
$( \pm)-9$

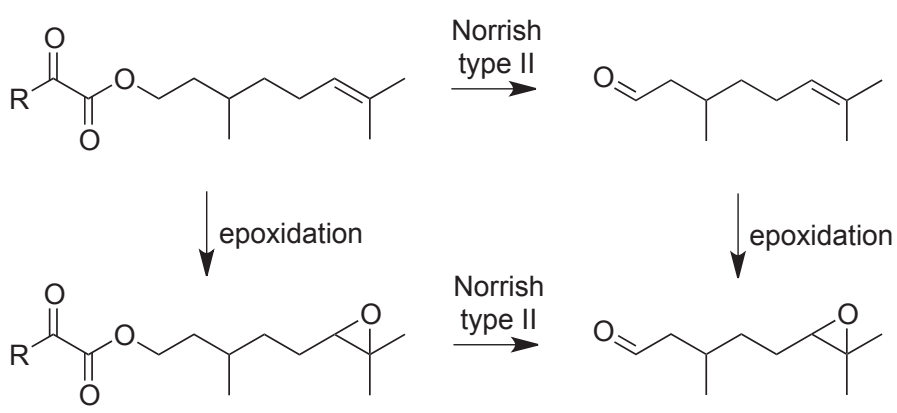

Scheme 4. Pathways leading to the light-induced formation of epoxide $( \pm)-9$ upon photoirradiation of citronellyl 2-oxoacetates in undegassed solution. ${ }^{[7]}$ formation of $( \pm)$-10 has also been confirmed by semi-empirical calculations, which predicted $( \pm)-\mathbf{1 0}$ to be about $5 \mathrm{kcal} \mathrm{mol}^{-1}$ more stable than $( \pm)-\mathbf{1 1}$, possibly due to ring strain. Similarly, both the singlet and the triplet states of the diradical susceptible to form $( \pm)$-10 were calculated to be lower in energy than those forming $( \pm)-11 .{ }^{[7]}$ It has further been shown that 2-oxoacetates with the lowest triplet states of $\pi-\pi^{*}$ character react less efficiently via the Norrish type II pathway ${ }^{[23,35]}$ but favour, in the presence of electron-rich alkenes, the Paternò-Büchi reaction from the upper $\mathrm{n}-\pi *$ triplet state. ${ }^{[50]}$

Other structural features susceptible to interfere with the desired Norrish type II fragmentation are groups that can generate remote radicals in the alkyl/aryl or ester chain, such as alkoxy groups (which facilitate hydrogen abstraction next to the oxygen atom), ${ }^{[51,52]}$ or sulphur and nitrogen atoms (which can induce an intramolecular hydrogen transfer followed by a hydrogen atom shift to generate a radical). ${ }^{[53]}$ Remote radicals can recombine with the hydroxyl radical photochemically generated at the carbonyl group of the 2-oxoacetate and thus form cyclic compounds (Scheme 6). Finally, $\delta$-halogen-substituted 2-oxoacetates have been found to undergo $\beta$-elimination. ${ }^{[54]}$ All of these side reactions compete with the Norrish type II reaction, but usually do not completely prevent it. With halogen, nitrogen and, to some extent, sulphur being less common heteroatoms in fragrances, these side reactions are not that important in the present context and are thus not further discussed.

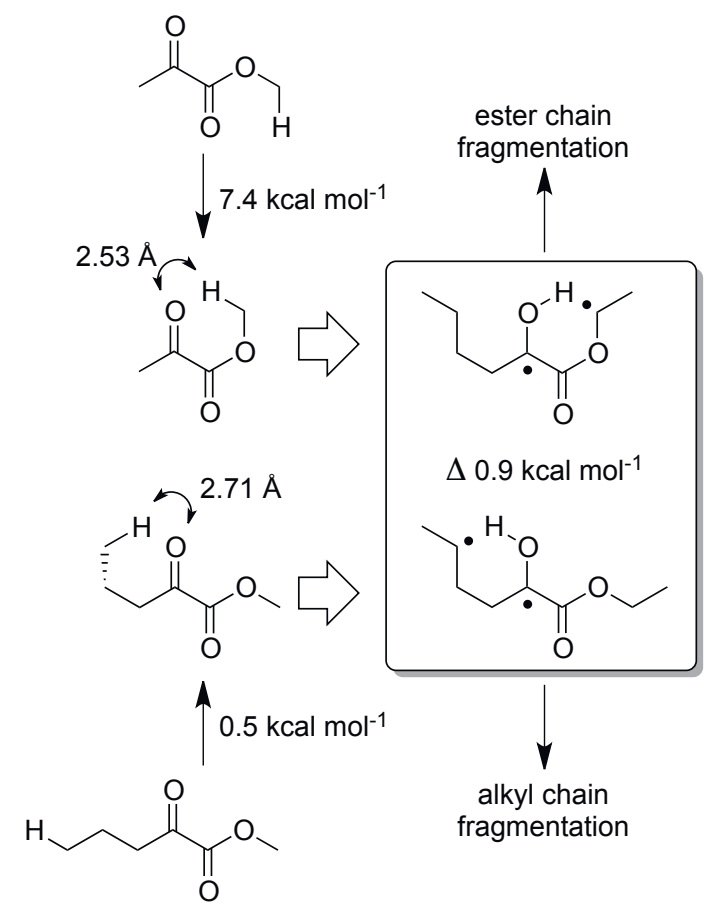

Scheme 5. Relative energies for the stability of different 1,4-diradicals and the conformers required for the Norrish type II alkyl or ester chain fragmentation of 2-alkyl-2-oxoacetates obtained by ab initio densityfunctional calculations. ${ }^{[7]}$

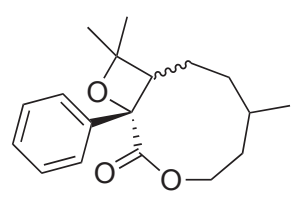

$( \pm)-10$

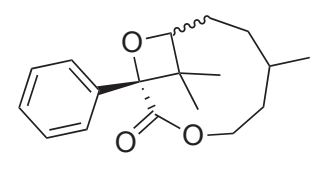

$( \pm)-11$

(not formed)
Fig. 2. Possible structures of oxetanes ( \pm )-10 and ( \pm )-11 formed by an intramolecular Paternò-Büchi reaction in the photoirradiation of 2-aryl-2oxoacetate $( \pm)$-8. Only the formation of $( \pm)-\mathbf{1 0}$ has been observed..$^{[7,10]}$ 
Not unexpectedly, the work on citronellyl 2-oxoacetates $( \pm)$ $\mathbf{2}-( \pm)-\mathbf{8}$ showed that both the structures of the substrate and those of the ester chain influence the formation of undesired side products. While alkyl chain fragmentation does usually not hinder the release of the fragrance, side reactions involving the ester chain typically reduce the total amount of fragrance that can be released. These reactions should thus be minimised.

Following a first proof of concept, additional 2-cyclohexyl-(12, 13) or 2-phenyl-2-oxoacetates (14, 15, Fig. 3) that release different fragrance molecules, such as anisaldehyde (with a sweet-flowery and slightly balsamic odour), (-)-menthone (providing a minty note), 2-phenylacetaldehyde (having a pungent-green floral and sweet odour) or citral (with a lemon-like smell) have been prepared and tested in practical application under realistic everyday life conditions. ${ }^{[7-9,55]}$

Photoirradiation of profragrance solutions with a xenon lamp or with outdoor sunlight released the target compounds in good yields; the release of ketones in particular turned out to be quite efficient. ${ }^{[7,8]}$ Fig. 4 shows the headspace concentrations of (-)-menthone released from profragrance $\mathbf{1 3}$ in a film of an all-purpose cleaner upon exposure to outdoor sunlight for a day. ${ }^{[9]}$ The recorded headspace concentrations follow the changing light intensity, which increases in the morning to reach a maximum at noon before decreasing again in the afternoon. The amount of (-)-menthone released into the headspace was more than one order of magnitude higher than the upper limit of the human olfactory threshold level of about $2200 \mathrm{ng} \mathrm{L}^{-1 ;[56]}$ the fragrance could thus easily be perceived.

In some water-based product formulations of functional perfumery, 2-oxoacetates have been found to slowly hydrolyse during storage, especially at extreme $\mathrm{pH}$, which limits the use of the profragrances in these applications. To stabilise 2-oxoacetates against premature degradation, two options have been investigated, namely grafting them onto polymers to form latex nanoparticles or encapsulating them in core-shell microcapsules. ${ }^{[6]}$<smiles>[R1]COC(=O)C1(O)c2ccccc2OC1[R]</smiles><smiles>[R]CSCC(C)OC(=O)C([R1])O</smiles>

Scheme 6. Examples for the formation of cyclic compounds by recombination of remote radicals with the hydroxyl radical photochemically generated at the carbonyl group of the 2-oxoacetate. ${ }^{[52,53]}$<smiles>COc1ccc(COC(=O)C(=O)C2CCCCC2)cc1</smiles>

12

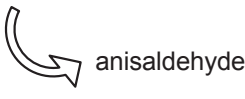<smiles>CN[C@@H]1CC[C@H](C(C)C)[C@H](OC(=O)C(=O)C2CCCCC2)C1</smiles><smiles>CC(C)=CCC/C(C)=C/COC(=O)C(=O)c1ccccc1</smiles>
15

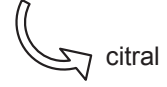

Fig. 3. Structures of 2-cyclohexyl- and 2-phenyl-2-oxoacetate profragrances 12-15 releasing different fragrance aldehydes and ketones. ${ }^{[7,8]}$

\subsection{Polymeric Systems}

In a different context, we have previously shown that a hydrophobic environment of a polymer in proximity to the covalent bond of a profragrance to be cleaved considerably retarded the fragrance release. ${ }^{[57]} \mathrm{We}$ thus expected that a 2-oxoacetate polymer conjugate might prevent the hydrolysis of the profragrance in application.

Polymers with 2-oxoacetate moieties in their side chains have been reported by Neckers and co-workers for possible uses as photo-cross-linkable materials in photolithography and imaging. ${ }^{[58]}$ The authors prepared two types of homopolymers with different orientations of the 2-oxoacetate in the side chain (16 and 17, Fig. 5). They found the photochemistry of these materials to be significantly different from that of the non-polymeric 2-oxoacetates reported previously. Both in neat polymer films and in aprotic solvents, hydrogen abstraction from adjacent side chains and radical coupling to form cross-linked materials occurred as the primary photoreaction (dotted lines), while $\gamma$-hydrogen abstraction within the same side chain and Norrish type II fragmentation was not observed. ${ }^{[58]}$

For the preparation of polymeric profragrance latexes, we first synthesised 2-oxo-2-(4-vinylphenyl)acetates (e.g. 18) as profragrance monomers. Radical co-polymerisation of the monomers with methyl methacrylate and 1,4-butanediol divinyl ether (used as a cross-linker) in an oil-in-water emulsion then afforded random co-polymer latexes such as $\mathbf{1 9}$ (Scheme 7). ${ }^{[6]}$

Alternatively, profragrance-containing core-shell microcapsules have been prepared by interfacial polymerisation of an etherified melamine-formaldehyde resin and poly(acrylamide-co-acrylic acid) of an oil-in-water emulsion, with the resin and the profragrance $(e . g .14)$ being part of the oil phase. ${ }^{6]}$

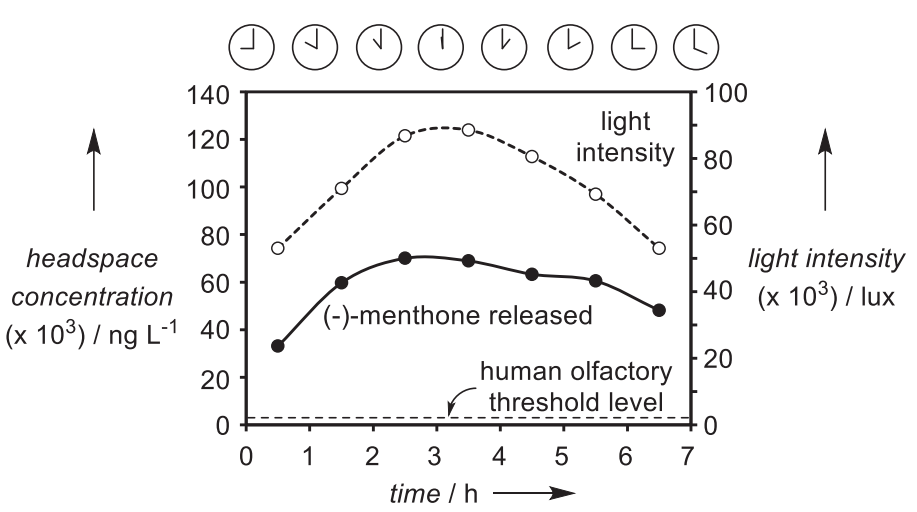

Fig. 4. Headspace concentrations of (-)-menthone released from profragrance $( \pm)-13$ at 0.3 wt-\% in a film of an all-purpose surface cleaner on glass exposed to outdoor sunlight between 9 am and 4 pm. ${ }^{[9]}$

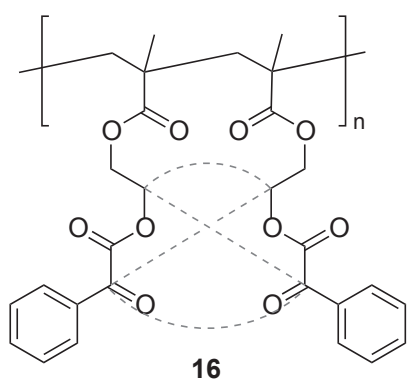

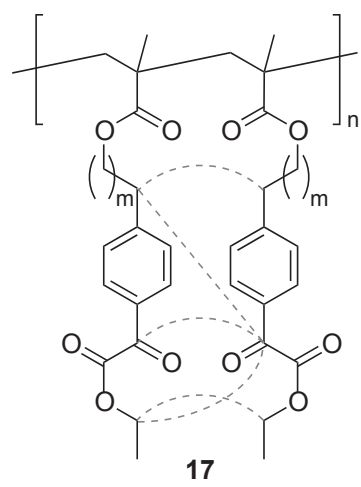

Fig. 5. Polymers with 2-oxoacetate moieties in their side chains. The dotted lines in grey show the possible sites for hydrogen abstraction and radical coupling in adjacent side chains to form cross-linked materials. ${ }^{[58]}$ 
Varying the amount of resin affords capsules with different shell thicknesses.

As shown for aged samples kept in an aqueous environment, both the latexes and the core-shell microcapsules stabilised the profragrances efficiently against hydrolysis. ${ }^{[6]}$ The controlled release of the fragrance from the obtained nanoparticle dispersions and from the core-shell microcapsules has been tested by headspace analysis in an aqueous surfactant emulsion on glass, as well as in a fabric softener application on cotton. Photoirradiation with a xenon lamp confirmed the formation of the fragrance as the result of the expected Norrish type II fragmentation in both cases. The example in Fig. 6 compares the headspace concentrations of 2-phenylethylaldehyde released from co-polymer 19, as well as from encapsulated and non-encapsulated profragrance $\mathbf{1 4}$ on cotton. ${ }^{[6]}$ With a low human olfactory threshold level of $0.72 \mathrm{ng} \mathrm{L}^{-1},{ }^{[56]} 2$-phenylacetaldehyde can easily be smelled in all cases. For the comparison of the data, it should be noted that the different delivery systems were indirectly deposited on the cotton surface from a fabric softener formulation. Differences in headspace concentrations thus reflect a combination of release efficiency and relative amount of surface deposition.

Although a certain amount of light-induced cross-linking of the 2-oxoacetate side chains in the latex nanoparticles cannot be ruled out, it has been demonstrated that the Norrish type II reaction efficiently takes place in a polymeric environment. ${ }^{[6]}$ Presumably the presence of the co-monomer kept the different 2-oxoacetate side chains at a sufficient distance to minimise cross-linking reactions. Furthermore, it has been shown that the nature of the coreshell microcapsules had no major influence on the photoreaction, thus allowing the use of different capsule wall chemistries. ${ }^{[4-6]}$ Polymer-based 2-oxoacetates at the nanometre (latexes) and micrometre scale (capsules) are thus efficient delivery systems for the light-induced release of fragrances in functional perfumery applications. [59]
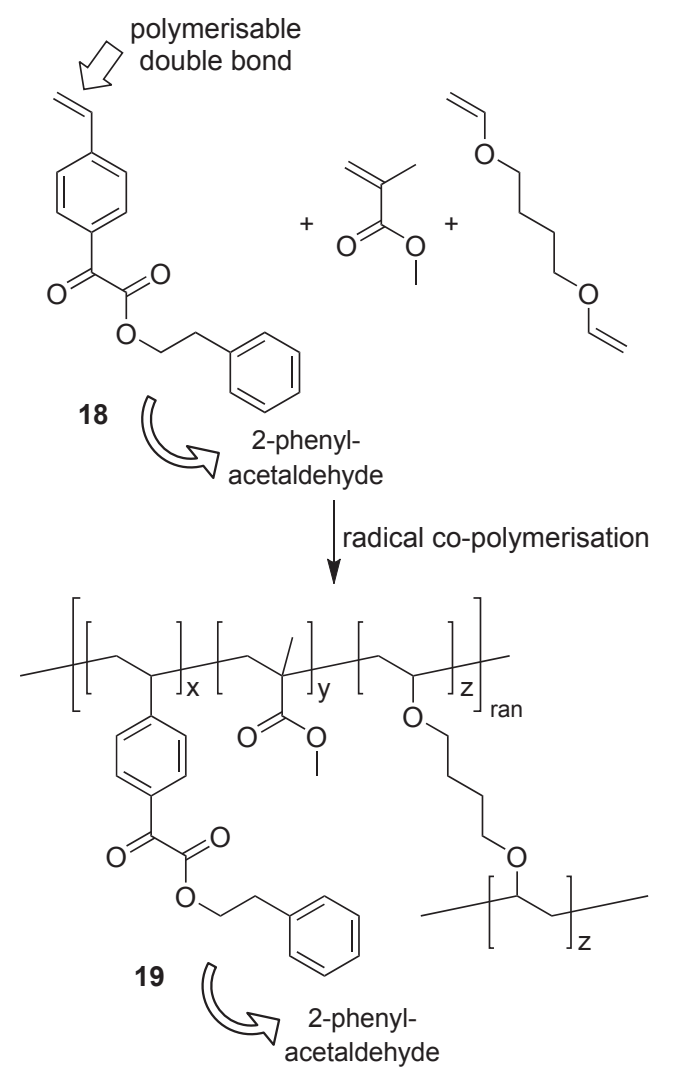

Scheme 7. Radical co-polymerisation of 2-oxo-2-(4-vinylphenyl)acetate profragrances in emulsion to form dispersions of latex nanoparticles (19: $x=29.9, y=70.0, z=0.1 \mathrm{~mol}-\%)^{[6]}$

\section{Bursting Capsules from Encapsulated 2-Oxoaceates}

The formation of gas ( $\mathrm{CO}$ and/or $\mathrm{CO}_{2}$ ) as a side product of the Norrish type II fragmentation has continuously been reported since the very first studies on the photoreaction of 2-oxoacetates (Schemes 1 and 2); ${ }^{[18,27,33,34]}$ however, no particular advantage had so far been taken from it. In the direct comparison of the light-induced release of 2-phenylacetaldehyde from profragrance 14 and from 14 encapsulated in poly(urea-urethane) core-shell microcapsules, we observed that the start of fragrance release was not retarded if the profragrance was encapsulated. ${ }^{[4]}$ It has also been shown that the onset of $\mathrm{CO}$ and $\mathrm{CO}_{2}$ formation was instantaneous once the light source was switched on, and the immediate fragrance release as a direct response to the photoirradiation has been explained by a burst of the microcapsules due to gas overpressure inside the capsule.

At first view, this seemed surprising because one might expect that the capsule wall would slow the photoreaction down (by absorbing part of the UV light) or, once the photoreaction took place, at least prevent rapid evaporation of the fragrance. Furthermore, it is known that small gases diffuse through polymer membranes; ${ }^{[60]}$ thus, building up a gas overpressure is only possible if the gas formation was much faster than its diffusion through the capsule wall. Upon irradiation with a xenon lamp, a series of 2-oxoacetates degraded in solution with half-life times of 15 to $40 \mathrm{~min},{ }^{[61]}$ which turned out to be sufficient to extend and/or burst core-shell microcapsules. ${ }^{[4]}$

The fact that encapsulated 2-oxoacetates burst core-shell microcapsules broadens the use of the technology for fragrance release. In addition to the encapsulation of pure profragrance 2-oxoacetates discussed so far (Fig. 7a), one can co-encapsulate other non-covalently linked perfumery compounds with the profragrance and thus allow the simultaneous light-induced release of fragrance aldehydes or ketones and other perfume materials (Fig. $7 b)$. Alternatively, one can use a non-profragrance 2-oxoacetate[62] only to generate the gas overpressure that cleaves the capsule to exclusively release other co-encapsulated, non-covalently linked fragrances (Fig. 7c). ${ }^{[4,5,63]}$

The different scenarios shown in Fig. 7 have been tested, and the successful release of the different fragrances has been demonstrated for all cases. ${ }^{[4,5]}$ Scheme 8 (left part) shows optical mi-

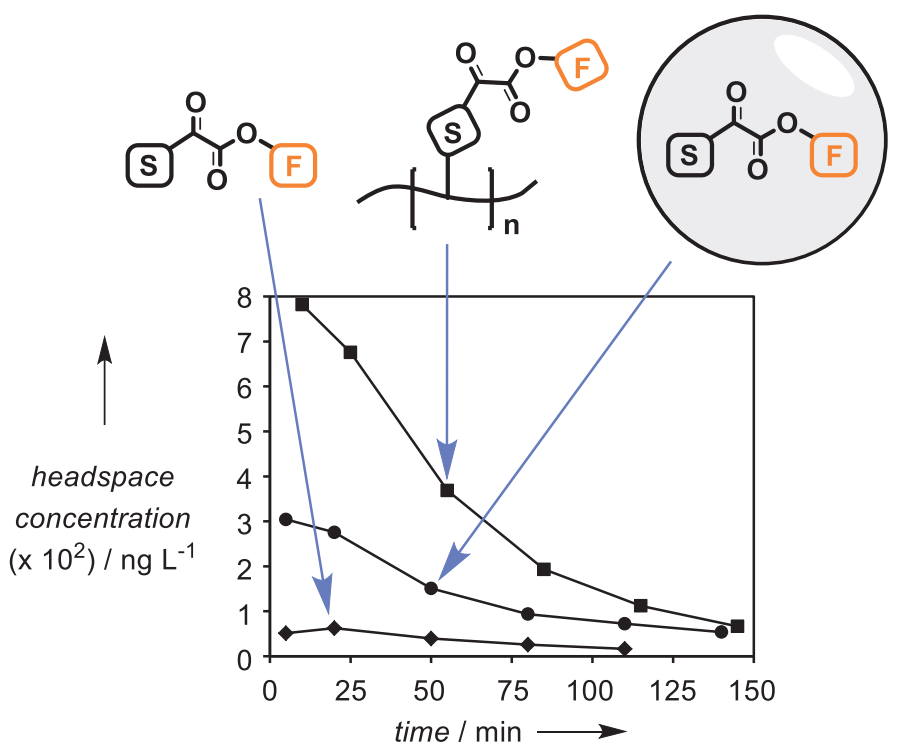

Fig. 6. Headspace concentrations of 2-phenylacetaldehyde released from co-polymer 19 (- - -) and from encapsulated (- - - ) and non-encapsulated $(-\rightarrow)$ profragrance 14 upon photoirradiation on cotton. ${ }^{[6]}$ All compounds have been tested at equimolar amounts of 2-phenylacetaldehyde $(0.026 \mathrm{mmol})$ to be released. 
croscopy pictures taken at different times of photoirradiation of poly(urea-urethane) core-shell microcapsules containing 2-oxoacetate $\mathbf{1}$ and a co-encapsulated fragrance molecule after deposition on a glass slide (corresponding to the setup in Fig. 7c). The photos were taken before irradiation (a) and after 60 (b) and $120 \mathrm{~s}$ (c) of irradiation with UV-A light. ${ }^{[63]}$ One can see the formation of gas bubbles inside the capsules (orange arrows), as well as the leakage of the oil phase out of the capsules (violet arrows). The right-hand side of Scheme 8 illustrates the different steps of the light-induced release of the fragrance from the capsules in accordance with the photographs. ${ }^{[64]}$ Although the irradiation conditions under the microscope with well-focused UV-A light are ideal, it is nevertheless remarkable that an efficient fragrance release can be achieved within 2 min of irradiation.

Various parameters, such as the structure and the amount of 2-oxoacetate used, the constitution of the oil phase to be encapsulated, the size of the capsules, and the composition and thickness of their wall, impact the performance of the delivery system and can be optimised in view of the targeted application. ${ }^{[4,5]}$ Because coreshell microcapsules used in applications of functional perfumery are typically cleaved by mechanical force through rubbing, the co-encapsulation of a photolabile 2-oxoacetate profragrance with other fragrance molecules (Fig. 7b) gives access to multi-stimuli responsive delivery systems that release different odours, depending on the order at which the different triggers are applied..5]

If low light intensities are applied or if the formation of the gas is not sufficient to burst the capsules, two scenarios for a trigger-dependent fragrance release are shown in Fig. 8. If the capsules are rubbed first and irradiated later (Fig. 8a), the co-encapsulated fragrance is released as a response to the mechanical cleavage of the capsule wall through rubbing, while the profragrance remains intact. Exposure to light then releases the second fragrance as a response to the photofragmentation of the 2-oxoacetate. On the other hand, if the capsules are first exposed to light and rubbed later, then the profragrance is slowly cleaved inside the capsules while (most of) the capsules remain intact. Rubbing then breaks the capsules and releases the two fragrances simultaneously (Fig. 8b). ${ }^{[5]}$

\section{Conclusions}

On exposure to UV-A light, 2-alkyl- and 2-aryl-2-oxoacetates $(\alpha$-ketoesters) fragment by intramolecular $\gamma$-hydrogen abstraction (Norrish type II pathway) to form a carbonyl compound (D) from the ester chain, carbon monoxide, and an aldehyde (J) from the 2-oxoacetate substrate (Scheme 2). Intermolecular hydrogen abstraction, e.g. in protic solvents, can form a hydroxyester (I), a dihydroxydiester $(\mathbf{B})$ or carbonyl compound $\mathbf{D}$, carbon monoxide, and aldehyde $\mathbf{J}$. If the carbonyl compound $\mathbf{D}$ is a fragrance aldehyde or ketone, the reaction can be used for the light-induced generation of volatile fragrances from less volatile precursors. The more selectively the photoreaction proceeds towards target compound $\mathbf{D}$ under ambient everyday life conditions, the more efficient the controlled fragrance release will be. The fact that at low 2-oxoacetate concentrations intramolecular hydrogen abstraction is preferred over intermolecular hydrogen abstraction is favour-
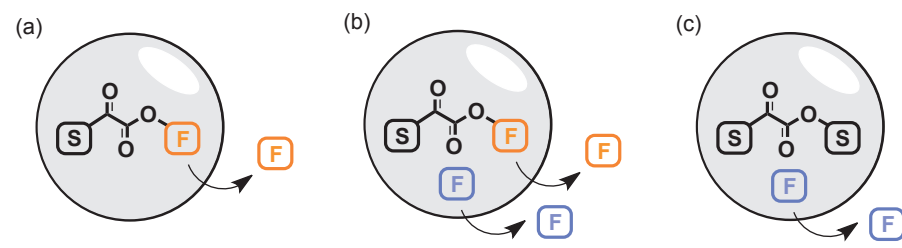

Fig. 7. Different scenarios for the light-induced release of fragrances from encapsulated 2-oxoacetates by using either a 2-oxoacetate profragrance $(a$ and $b)$ or a non-profragrance 2-oxoacetate (c) to generate a gas that bursts the capsules. able for the targeted applications. Furthermore, the presence of oxygen does not prevent the formation of carbonyl compound $\mathbf{D}$ from the ester chain of the precursor, but forms a carboxylic acid (R) and carbon dioxide as the main products from the 2-oxoacetate structure.

It has been shown that 2-oxoacetates are indeed suitable delivery systems for the light-induced release of fragrances. Depending on the structure of the fragrance to be released, additional side reactions have been observed, such as the photochemical epoxidation of double bonds or the addition of alkenes to the reactive 2-oxoacetate carbonyl group in a Paternò-Büchi reaction. Both non-polymeric structures and polymer conjugates successfully released the targeted fragrances in applications of functional perfumery. The rate of fragrance release depends on the intensity of the irradiating light and proceeds in a range varying between several minutes and a couple of hours. As a consequence of the rapid generation of gas overpressure resulting from the formation of carbon monoxide and dioxide as side products in the photoreaction at high light intensities, encapsulated 2-oxoacetates allow the light-induced burst of core-shell microcapsules, which considerably extends the use of these structures as photoresponsive materials. Finally, the combination of the light dependence of the photoreaction of 2-oxoacetates with the mechanical cleavage of core-shell microcapsules gave access to multi-stimuli responsive delivery systems, which can release different odours depending on the order at which the different triggers are applied.

The present review illustrates the development of the photochemistry of 2-oxoacetates over almost six decades. It shows the evolution from the fundamental understanding of the reaction mechanism to concrete applications in fragrance delivery and demonstrates how basic understanding of molecular reactivity can lead to useful tools for everyday life.
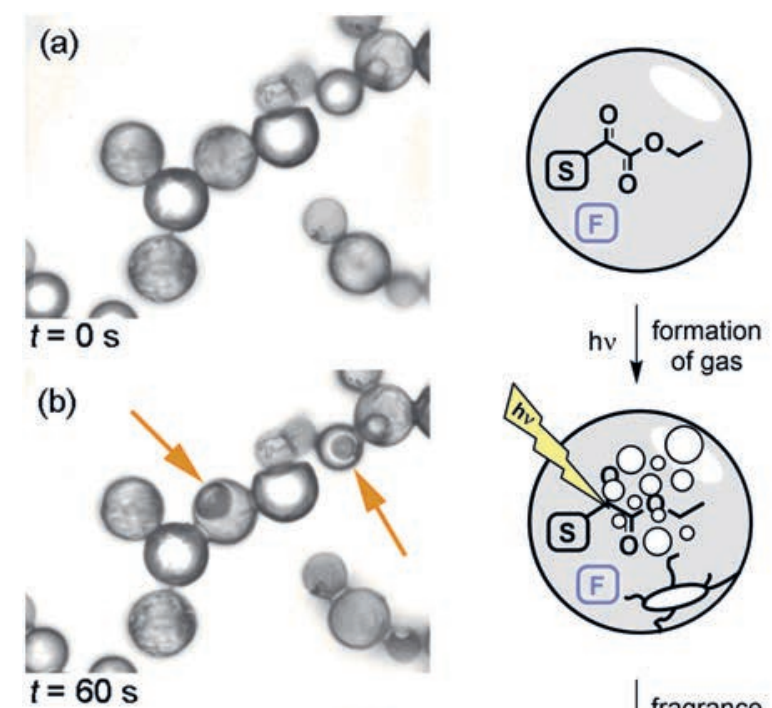

(c)
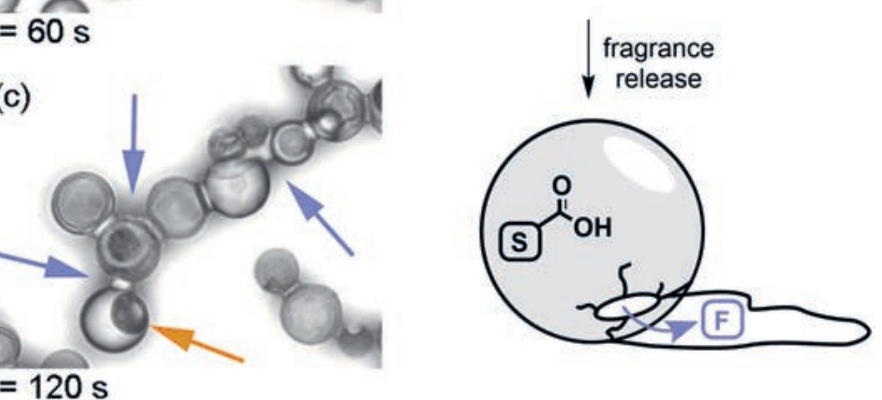

$t=120 \mathrm{~s}$

Scheme 8. Optical microscopy pictures taken after different times of photoirradiation and schematic representation of the stepwise fragrance release from poly(urea-urethane) core-shell microcapsules containing 2-oxoacetate 1 and a co-encapsulated fragrance molecule. ${ }^{[63]}$ Orange arrows show the formation of gas bubbles inside the capsules; violet arrows indicate the leakage of the oil phase out of the capsules. ${ }^{[64]}$ 


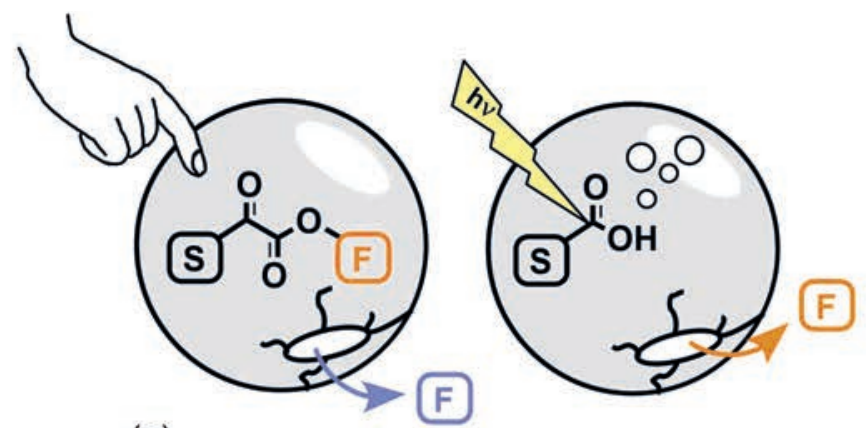

(a) first trigger

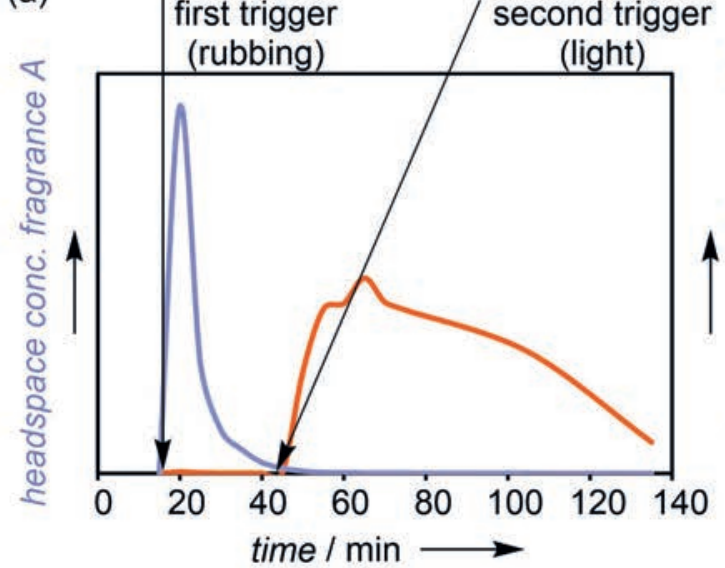

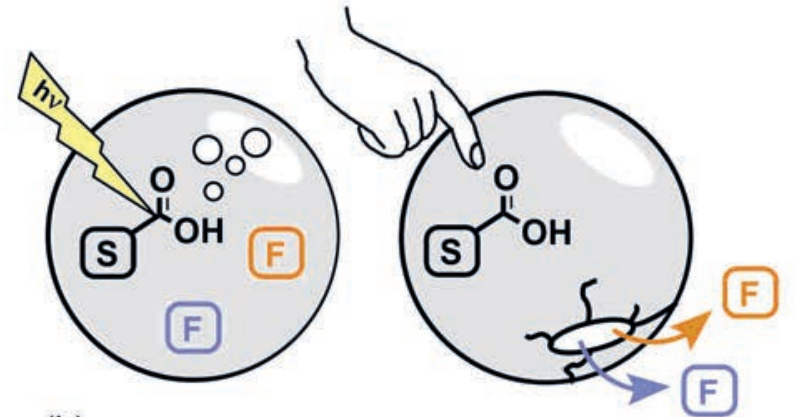

(b)
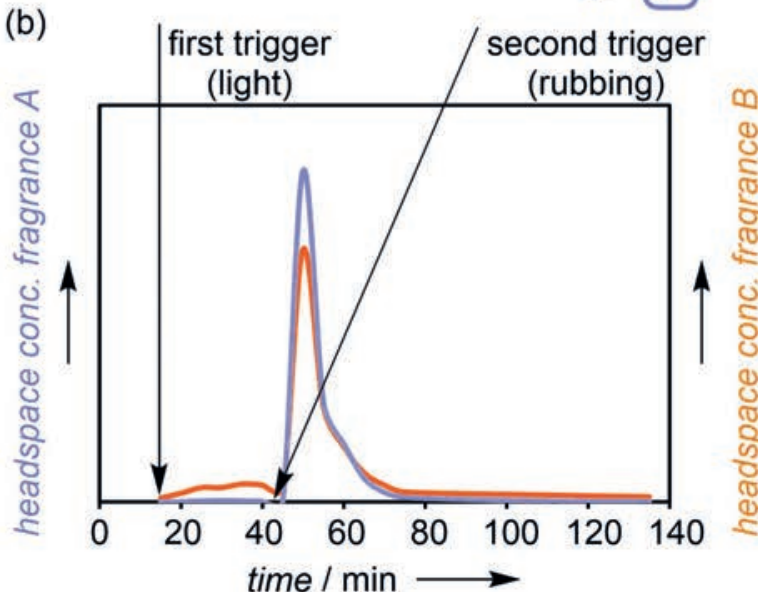

Fig. 8. Development of multi-trigger systems by combining the light-induced fragrance release from profragrances with a mechanical cleavage of the capsules induced by rubbing. Depending on the order at which the different triggers are applied (rubbing followed by exposure to light (a) or exposure to light and then rubbing (b)), different odours can be released at different times. ${ }^{[5]}$

\section{Acknowledgements}

I thank all my colleagues at Firmenich who have been involved in exploring the photochemistry of 2-oxoacetates. In particular, I am grateful to my co-workers Nicolas Paret, Dr. Damien Berthier, Alain Trachsel, Barbara Buchs (Levrand), Dr. Jean-Yves de Saint Laumer and Sabine Leocata (Rochat) for their contributions to the different projects, as well as to Dr. Gary Womack, Dr. Huda Jerri, Dr. Lahoussine Ouali and Dr. Daniel Benczédi for numerous discussions and continuous support. I also thank Dr. Esther Oliveros, Dr. Jana Pika and Dr. Sina Escher for their input at the early stage of our work.

Received: November 6, 2019

[1] For recent reviews, see for example: a) I. T. Carvalho, B. N. Estevinho, L. Santos, Int. J. Cosmet. Sci. 2016, 38, 109; b) L. He, J. Hu, W. Deng, Polym. Chem. 2018, 9, 4926; c) R. Kaur, D. Kukkar, S. K. Bhardwaj, K.-H. Kim, A. Deep, J. Controlled Release 2018, 285, 81; d) K. Bruyninckx, M. Dusselier, ACS Sus. Chem. Eng. 2019, 7, 8041.

[2] For reviews, see for example: a) A. Herrmann, Angew. Chem. Int. Ed. 2007, 46, 5836; Angew. Chem. 2007, 119, 5938; b) A. Herrmann, Chem. Unserer Zeit 2015, 49, 36; c) A. Herrmann, Chimia 2017, 71, 414.

[3] a) J. Marques, L. F. Oliveira, R. T. Pinto, P. J. G. Coutinho, P. Parpot, J. R. Góis, J. F. J. Coelho, F. D. Magalhães, C. J. Tavares, Int. J. Photoenergy 2013, 712603; b) B. Tylkowski, M. Giamberini, T. Underiner, S. Fernandez Prieto, J. Smets, Macromol. Symp. 2016, 360, 192.

[4] N. Paret, A. Trachsel, D. L. Berthier, A. Herrmann, Angew. Chem. Int. Ed. 2015, 54, 2275; Angew. Chem. 2015, 127, 2303.

[5] N. Paret, A. Trachsel, D. L. Berthier, A. Herrmann, Macromol. Mater. Eng. 2019, 304, 1800599.

[6] M. Charlon, A. Trachsel, N. Paret, L. Frascotti, D. L. Berthier, A. Herrmann, Polym. Chem. 2015, 6, 3224.

[7] S. Rochat, C. Minardi, J.-Y. de Saint Laumer, A. Herrmann, Helv. Chim. Acta 2000, 83, 1645

[8] B. Levrand, A. Herrmann, Chimia 2007, 61, 661.

[9] A. Herrmann, C. Debonneville, V. Laubscher, L. Aymard, Flavour Fragrance J. 2000, 15,415 .

[10] S. Hu, D. C. Neckers, J. Org. Chem. 1997, 62, 6820.

[11] For reviews on fragrance release based on the Norrish type II reaction, see: a) A. Herrmann, Spectrum 2004, 17(2), 10 and 19; b) A. Herrmann, Photochem. 2019, 46, 242.
[12] a) B. Levrand, A. Herrmann, Photochemistry Photobiol. Sci. 2002, 1, 907; b) A. G. Griesbeck, O. Hinze, H. Görner, U. Huchel, C. Kropf, U. Sundermeier, T. Gerke, Photochemistry Photobiol. Sci. 2012, 11, 587; c) A. G. Griesbeck, B. Porschen, C. Kropf, A. Landes, O. Hinze, U. Huchel, T. Gerke, Synthesis 2017, 49, 539.

[13] S. Derrer, F. Flachsmann, C. Plessis, M. Stang, Chimia 2007, 61, 665.

[14] A. Herrmann, Photochem. Photobiol. Sci. 2012, 11, 446.

[15] For some recent work, see also: a) A. Trachsel, B. Buchs, A. Herrmann, Photochem. Photobiol. Sci. 2016, 15, 1183; b) M. Liu, J. Han, C. Yan, Z. Guo, Z. Xiao, W.-H. Zhu, ACS Appl. Bio Mater. 2019, 2, 4002.

[16] a) R. G. W. Norrish, M. E. S. Appleyard, J. Chem. Soc. 1934, 874; b) C. H. Bamford, R. G. W. Norrish, J. Chem. Soc. 1935, 1504.

[17] For general reviews on the Norrish type II reaction of phenyl ketones, see for example: a) P. J. Wagner, Top. Curr. Chem. 1976, 66, 1; b) J. C. Scaiano, E. A. Lissi, M. V. Encina, Rev. Chem. Intermed. 1978, 2, 139.

[18] G. S. Hammond, P. A. Leermakers, N. J. Turro, J. Am. Chem. Soc. 1961, 83, 2395.

[19] E. S. Huyser, D. C. Neckers, J. Org. Chem. 1964, 29, 276

[20] Y. Chiang, A. J. Kresge, P. Pruszynski, N. P. Schepp, J. Wirz, Angew. Chem. Int. Ed. 1990, 29, 792; Angew. Chem. 1990, 102, 810.

[21] N. C. Yang, A. Morduchowitz, J. Org. Chem. 1964, 29, 1654.

[22] T. Fujisawa, B. M. Monroe, G. S. Hammond, J. Am. Chem. Soc. 1970, 92, 542.

[23] P. A. Leermakers, P. C. Warren, G. F. Vesley, J. Am. Chem. Soc. 1964, 86, 1768 .

[24] T. Tominaga, Y. Odaira, S. Tsutsumi, Bull. Chem. Soc. Jpn. 1966, 39, 1824.

[25] R. S. Davidson, D. Goodwin, J. Chem. Soc., Perkin Trans. 2 1982, 993.

[26] a) M. V. Encinas, E. A. Lissi, A. Zanocco, L. C. Stewart, J. C. Scaiano, Can. J. Chem. 1984, 62, 386; b) J. C. Scaiano, M. V. Encinas, E. A. Lissi, A. Zanocco, P. K. Das, J. Photochem. 1986, 33, 229.

[27] S. Hu, D. C. Neckers, J. Org. Chem. 1996, 61, 6407.

[28] A. V. Fedorov, E. O. Danilov, M. A. J. Rodgers, D. C. Neckers, J. Am. Chem. Soc. 2001, 123, 5136.

[29] a) A. G. Merzlikine, S. V. Voskresensky, E. O. Danilov, M. A. J. Rodgers, D. C. Neckers, J. Am. Chem. Soc. 2002, 124, 14532; b) A. G. Merzlikine, S. V. Voskresensky, E. O. Danilov, A. V. Fedorov, M. A. J. Rodgers, D. C. Neckers, Photochem. Photobiol. Sci. 2004, 3, 892.

[30] A. G. Merzlikine, S. V. Voskresensky, E. O. Danilov, D. C. Neckers, A. V. Fedorov, Photochem. Photobiol. Sci. 2007, 6, 608.

[31] a) J. Grotewold, C. M. Previtali, D. Soria, J. C. Scaiano, J. Chem. Soc., Chem. Commun. 1973, 207; b) R. D. Small Jr., J. C. Scaiano, J. Am. Chem. Soc. 1978, 100, 4512; c) M. Yoshioka, K. Funayama, T. Hasegawa, J. Chem. Soc., Perkin Trans. 1 1989, 1411.

[32] a) R. S. Davidson, D. Goodwin, J. E. Pratt, Tetrahedron 1983, 39, 1069; b) R. S. Davidson, D. Goodwin, J. E. Pratt, Tetrahedron 1983, 39, 2373. 
[33] M. C. Pirrung, R. J. Tepper, J. Org. Chem. 1995, 60, 2461.

[34] S. Hu, D. C. Neckers, J. Photochem. Photobiol., A 1998, 118, 75.

[35] R. W. Binkley, J. Org. Chem. 1976, 41, 3030.

[36] a) H. A. J. Carless, G. K. Fekarurhobo, Tetrahedron Lett. 1983, 24, 107; b) H. Aoyama, M. Sakamoto, K. Yoshida, Y. Omote, J. Heterocycl. Chem. 1983, 20, 1099.

[37] a) F. Kasten, G. Czeplak, Sol. Energy 1980, 24, 177; b) J. E. Frederick, H. E. Snell, E. K. Haywood, Photochem. Photobiol. 1989, 50, 443; c) G. Rottman, J. Atmos. Sol.-Terr. Phys. 1999, 61, 37.

[38] a) E. Breitmaier, 'Terpenes - Flavors, Fragrances, Pharmaca, Pheromones', Wiley-VCH, Weinheim, 2006; b) 'The Chemistry and Biology of Volatiles', Ed. A. Herrmann, John Wiley \& Sons, Chichester, 2010; c) G. Ohloff, W. Pickenhagen, P. Kraft, 'Scent and Chemistry', Wiley-VCH, Weinheim, 2011.

[39] a) S. Arctander, 'Perfume and Flavor Chemicals', published by the author, Montclair, 1969; b) H. Surburg, J. Panten, 'Common Fragrance and Flavor Materials: Preparation, Properties and Uses', 5th Edn., Wiley-VCH, Weinheim, 2006

[40] The perception and description of odours is quite subjective and may vary from one individual to another. The odour descriptors used here are those reported in the literature (ref. [39]).

[41] R. M. Sayre, C. Cole, W. Billhimer, J. Stanfield, R. D. Ley, Photodermatol. Photoimmunol. Photomed. 1990, 7, 159.

[42] Y. Sawaki, Y. Ogata, J. Am. Chem. Soc. 1981, 103, 6455.

[43] a) T. R. Evans, P. A. Leermakers, J. Am. Chem. Soc. 1968, 90, 1840; b) R. S. Davidson, D. Goodwin, P. Fornier de Violet, Tetrahedron Lett. 1981, 22, 2485 ; c) A. L. Zanocco, E. A. Soto, E. A. Lissi, J. C. Scaiano, J. Photochem. Photobiol., A 1990, 53, 77.

[44] H. Ihmels, J. R. Scheffer, Tetrahedron 1999, 55, 885

[45] D. Sengupta, A. Bhattacharyya, R. Sumathi, A. K. Chandra, J. Photochem. Photobiol., A 1995, 86, 161.

[46] S. Hu, D. C. Neckers, J. Org. Chem. 1997, 62, 564.

[47] a) M. D'Auria, R. Racioppi, Molecules 2013, 18, 11384; b) M. D'Auria Photochem. Photobiol. Sci. 2019, 18, 2297.

[48] a) S. Buhr, A. G. Griesbeck, J. Lex, J. Mattay, J. Schröer, Tetrahedron Lett. 1996, 37, 1195; b) M. D’Auria, L. Emanuele, R. Racioppi, Photochem. Photobiol. Sci. 2003, 2, 904; c) M. D’Auria, L. Emanuele, R. Racioppi, Lett. Org. Chem. 2008, 5, 249.

[49] See for example: a) K. Shima, T. Sawada, H. Yoshinaga, Bull. Chem. Soc. Jpn. 1978, 51, 608; b) R. Pelzer, H.-D. Scharf, H. Buschmann, J. Runsink, Chem. Ber. 1989, 122, 1187.

[50] Y. Kaneko, S. Hu, D. C. Neckers, J. Photochem. Photobiol., A 1998, 114, 173.

[51] a) G. A. Kraus, Y. Wu, J. Am. Chem. Soc. 1992, 114, 8705; b) S. Hu, D. C Neckers, J. Org. Chem. 1997, 62, 755; c) S. Hu, D. C. Neckers, J. Chem. Soc., Perkin Trans. 2 1997, 1751.

[52] a) S. P. Pappas, B. C. Pappas, J. E. Blackwell Jr., J. Org. Chem. 1967, 32, 3066; b) S. P. Pappas, J. E. Alexander, R. D. Zehr Jr., J. Am. Chem. Soc. 1970, 92, 6927.
[53] a) S. Hu, D. C. Neckers, Tetrahedron 1997, 53, 2751; b) S. Hu, D. C. Neckers, Tetrahedron 1997, 53, 7165.

[54] S. Hu, D. C. Neckers, J. Org. Chem. 1997, 62, 7827.

[55] J. Pika, A. Herrmann, C. Vial (to Firmenich SA), PCT Int. Patent Appl. WO 99/60990, 1999.

[56] L. J. van Gemert, 'Odour Thresholds: Compilations of Odour Threshold Values in Air, Water and Other Media', Oliemans Punter \& Partners BV, Utrecht, 2003.

[57] a) A. Trachsel, J.-Y. de Saint Laumer, O. P. Haefliger, A. Herrmann, Chem. Eur. J. 2009, 15, 2846; b) D. L. Berthier, N. Paret, A. Trachsel, A. Herrmann, Bioconjugate Chem. 2010, 21, 2000.

[58] a) S. Hu, A. Mejiritski, D. C. Neckers, Chem. Mater. 1997, 9, 3171; b) S. Hu, D. C. Neckers, Macromolecules 1998, 31, 322.

[59] a) A. Herrmann, D. Berthier, N. Paret, M. Therrien (to Firmenich SA), PCT Int. Patent Appl. WO 2013/050303, 2013; b) D. Berthier, A. Herrmann, N. Paret, L. Ouali (to Firmenich SA), PCT Int. Patent Appl. WO 2013/079435, 2013.

[60] See for example: G. Maier, Angew. Chem. Int. Ed. 2013, 52, 4982; Angew. Chem. 2013, 125, 5082.

[61] Please note that the rate of photolysis (and thus the efficiency of gas formation) depends on the structure of the 2-oxoacetate and on the intensity of the irradiating light source. Irradiations with a xenon lamp were carried out with a UV-A light power of $c a .3 .1 \mathrm{~mW} \mathrm{~cm}^{-2}$ (corresponding to $c a .45^{\prime} 000 \mathrm{lux}$ ).

[62] 2-Oxoacetic acids ( $\alpha$-ketoacids) also decarboxylate photochemically. However, their fragmentation mechanism is different from that of the 2-oxoacetates and not further discussed in the present work.

[63] A. Herrmann, D. Berthier, N. Paret, A. Trachsel (Firmenich SA), PCT Int. Patent Appl. WO 2014/187833, 2014.

[64] A video showing the light-induced burst of core-shell microcapsules under the microscope is available on the internet as part of the Supporting Information of ref. [4].

\section{License and Terms}

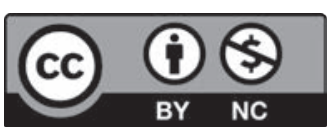

This is an Open Access article under the terms of the Creative Commons Attribution License CC BY_NC 4.0. The material may not be used for commercial purposes.

The license is subject to the CHIMIA terms and conditions: (http:// chimia.ch/component/sppagebuilder/?view=page \&id=12).

The definitive version of this article is the electronic one that can be found at doi:10.2533/chimia.2020.39 